\title{
BMJ Open Distribution of care expenditures for men and women with type 2 diabetes treated in primary care in the Netherlands: a case-control study (ZODIAC-59)
}

\author{
M R J Mevissen, ${ }^{1}$ Rose Julie Geurten (D) , ${ }^{2}$ S H Hendriks, ${ }^{3}$ Arianne Elissen (D) , ${ }^{4}$ \\ Peter Ruben van Dijk (i) , ${ }^{5,6}$ Henk J G Bilo ${ }^{1}$
}

To cite: Mevissen MRJ, Geurten RJ, Hendriks SH, et al. Distribution of care expenditures for men and women with type 2 diabetes treated in primary care in the Netherlands: a case-control study (ZODIAC-59). BMJ Open 2022;12:e052592. doi:10.1136/ bmjopen-2021-052592

- Prepublication history and additional supplemental material for this paper are available online. To view these files, please visit the journal online (http://dx.doi.org/10.1136/ bmjopen-2021-052592).

Received 20 April 2021 Accepted 11 January 2022

Check for updates

(C) Author(s) (or their employer(s)) 2022. Re-use permitted under CC BY-NC. No commercial re-use. See rights and permissions. Published by BMJ.

For numbered affiliations see end of article.

Correspondence to Dr Peter Ruben van Dijk; p.r.van.dijk@umcg.nl

\section{ABSTRACT}

Objective This study aims to provide insight into the distribution of care expenditures for patients with type 2 diabetes mellitus (T2DM) — across multiple healthcare service categories and medical specialties-who receive diabetes care in the primary care setting.

Design Observational, matched case-control study. Setting In the Netherlands, T2DM-specific care is mainly provided in the primary care setting. However, many patients with T2DM also use secondary care for complications and comorbidities, either related or unrelated to their diabetes.

Participants Patients with T2DM receiving diabetes care in primary care and participating in the Dutch Zwolle Outpatient Diabetes project Integrating Available Care cohort in the year 2011 were matched to persons without T2DM. Matching (1:2 ratio) was performed based on age, gender and socioeconomic status. Clinical data were combined with an all-payer claims database from 2011.

Results In total, 43775 patients with T2DM were identified of whom 37240 could be matched with 74480 controls. Total secondary care expenditures were $€ 94705$ 814 , with a total annual median expenditure per patient of $€ 2133$ (1161 to 3340) for men and $€ 2,535$ (1374 to 5105) for women. The largest share of expenditures was on medication $(26 \%)$, followed by secondary care $(23 \%)$ and primary care services related (23\%) to T2DM. The five most expensive specialties were: cardiology, surgery, internal medicine, orthopaedics and ophthalmology. Care expenditures for T2DM patients were twofold higher than those for persons without T2DM. Healthcare expenditures showed a skewed distribution, indicating that a small part of the studied population is responsible for a considerable part of the costs.

Conclusions Expenditures among primary care treated T2DM patients are higher than non-diabetic matched controls. Medication is the largest share of T2DM care expenditures. The present study provides insights into healthcare expenditures for T2DM; this may enable more efficient healthcare planning and reimbursement.
Strengths and limitations of this study

- This manuscript provides comprehensive data on the distribution of expenditures on patients with type 2 diabetes mellitus (T2DM) in the Netherlands.

- The results shown in this manuscript suggest that secondary care costs are high, even when the principal care for T2DM patient is concentrated with the general practitioner.

- The data we showed are from 2011 and may be outdated.

\section{INTRODUCTION}

Type 2 diabetes mellitus (T2DM) is one of the most common chronic diseases worldwide. ${ }^{1}$ Management of T2DM includes among other optimalisation of lifestyle, monitoring of blood glucose levels, administration of blood glucose lowering medication (eg, metformin or insulin) and the treatment of associated conditions such as hypertension and dyslipidaemia. ${ }^{2}$ These measures aim to prevent the development of microvascular and macrovascular complications associated with T2DM. In the Netherlands, over $80 \%$ of all patients with T2DM are treated in the primary care setting (ie, general practice). ${ }^{3}$ The quality of primary care for diabetes has improved since the introduction of integrated diabetes care in parts of the Netherlands in $1998 .{ }^{4}$ Diabetes care in the Netherlands is now considered well organised. ${ }^{5}$ Integrated diabetes care in primary care is provided by care groups; that is, regional health care provider groups consisting general practitioners and affiliated personnel from various disciplines.

In general, the healthcare expenditures for T2DM patients are higher than those for persons without T2DM. ${ }^{6}$ In Italy, average expenditures per T2DM patient were $€ 3661$, 
whereas average spending for patients without T2DM was $€ 896$ in 2003. In Germany, the average expenditures per T2DM patient were $€ 4957$ in 2009 , which was almost two times as high as the average expenditures for persons without T2DM. ${ }^{7}$ It has been suggested that this difference in expenditures can be explained by more frequent use of inpatient care among patients with T2DM. ${ }^{6}$ In addition, concurrent morbidities and the presence of microvascular and macrovascular complications also are associated with higher costs in patients with T2DM..$^{8-10}$

It is often assumed that concentrating diabetes care in a primary care setting (rather than in secondary care) leads to lower costs. However, detailed insight into the expenditures for patients with T2DM treated in primary care, with additional focus on expenditures for secondary care, is of importance for healthcare planning, reimbursement strategies and policymaking. To provide such insight, we aimed to specify a comprehensive overview of the distribution of healthcare expenditures across primary care, secondary care and medication for patients with T2DM who receive diabetes care in the primary care setting in 2011. In this overview, we compared patients with T2DM to persons without T2DM. Additionally, as T2DM expresses differently in men compared with women, it was decided to show the results gender specific. ${ }^{11}$

\section{PATIENTS AND METHODS}

\section{Design and aim}

In this observational study, we aimed to provide a comprehensive overview of the distribution of healthcare expenditures across primary care, secondary care and medication for patients with T2DM who receive diabetes care in the primary care setting. Additionally, using a matched case-control design, the expenditures for T2DM patients were compared with a non-T2DM population, also taking gender into account.

\section{Outcomes}

The primary outcome was total secondary care expenditures (in euros $(€)$ ) for T2DM patients treated for diabetes in the primary care setting. In order to provide an overview of the distribution, a subdivision of secondary care expenditures per (1) medical specialty, (2) number of treatments and (3) gender was made. The secondary care expenditures were also compared with expenditures for the non-T2DM control population (4). In addition to secondary care expenditures, we analysed expenditures of the following categories: primary care services excluding care related to T2DM, primary care services including care related to T2DM and medication (all medication, not only T2DM-related medication). For these categories, the distinctions for gender and the T2DM population and the control group were also made.

The number of treatments was described by the diagnosis treatment combinations (DTCs). In the Netherlands, specialised care is reimbursed via DTCs (in Dutch: 'Diagnose Behandel Combinatie' (DBC)). Each DTC contains information about the medical specialty of the treating physician, diagnosis and treatment provided. In 2011, the lead-time of a DTC was a maximum of 1 year. The total secondary expenditures were calculated by multiplying the number of DTCs by the median price.

\section{Population and data collection}

For the T2DM population, adult ( $>18$ years) persons with T2DM participating in the Zwolle Outpatient Diabetes project Integrating Available Care (ZODIAC) project were included. The ZODIAC project study initiated in 1998 and encompasses a database containing over 20 years of (benchmark) data on diabetes care in the primary care setting. The main aim of the ZODIAC study was to evaluate shared care for persons with T2DM in a selection of primary care regions in the Netherlands. As part of the ZODIAC project, data on patients with T2DM diabetes were collected annually using standardised electronic data forms. Over the years, an increasing amount of care groups shared their data with the ZODIAC project annually. The design and methods of data collection of the original ZODIAC study have been described in detail previously. ${ }^{12} 13$ The Knowledge Center for Integrated care in Zwolle collected the ZODIAC data. For the current study, all available patients with T2DM of the 2011 ZODIAC cohort were included. The data of this T2DM cohort were linked to the Dutch all-payer claims database (APCD) managed by Vektis. Vektis is an executive organisation of health insurers in the Netherlands that collects claims data of all health insurers. As a result, Vektis manages an APCD covering all Dutch citizens. ${ }^{14}$ Linkage of the ZODIAC and the APCD were done using the unique Citizen Service Number or the personal insurance number and date of birth. This was performed by an independent organisation (Zorg-TTP) and resulted in a fully anonymised database. The combined database was housed within the secure environment of Vektis.

Patients with T2DM treated in primary care were identified using their postal code and the diabetes-related code (in Dutch; 'diabeteszorgbeter project code') 701013029, 701013030 of 701014483 for the period 2006 to 2008 and using the primary care DBC code 13029 or 13030 from 2009 onwards. Persons treated in secondary care were identified using the secondary care DBC code 221, 222 or 223. In addition, the pharmacy codes A10Axxx of A10Bxxx were used to identify additional patients. The T2DM group was matched to a control group in a 1:2 ratio based on gender, age, postal code and region (to allow for comparison of people with a matching socioeconomic socioeconomic status) as these variables may influence healthcare expenditures. The control groups contained persons without T2DM derived from the APCD.

Patient and public involvement

No patient involved. 


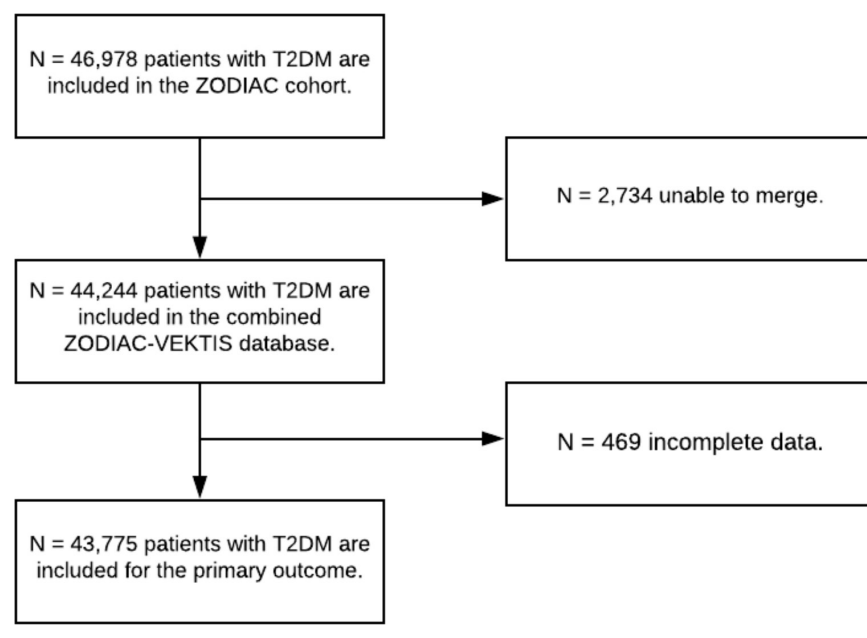

Figure 1 Flowchart of inclusion for the primary outcome of this study. T2DM, type 2 diabetes mellitus.

\section{Statistical analyses}

Data were analysed descriptively. Frequencies, percentages, means with SDs and medians with IQRs were used to describe the outcomes for normally and non-normally distributed data, respectively. All expenditures were presented in Euro. Statistical analysis was done with the software programmes Microsoft Excel 2019 and SPSS (IBM SPSS Statistics for Windows, V.20.0. Armonk, New York: IBM).

\section{RESULTS}

\section{Population}

In total, 44244 patients or $94 \%$ of patients with T2DM in the 2011 ZODIAC cohort could be retraced within the APCD (figure 1). For 469 patients, insufficient data were available. Ultimately, data on 43775 patients $(49 \%$ men and $51 \%$ women) were available. For the casecontrol analysis of this study, another 7004 patients with T2DM were excluded from the combined ZODIAC and APCD database because of missing data per patient in the year 2011. Therefore, after matching, a total number 37240 patients with T2DM (51\% women) were matched to 74480 controls without T2DM.

\section{Expenditures of patients with T2DM}

Total secondary care expenditures were $€ 94705814$ for patients with T2DM treated for diabetes in the primary care setting. These expenditures were reimbursed under 92971 DTCs. Of total expenditures, $46 \%$ was spent on men and $54 \%$ was reimbursed for women. The expenditures and the number of DTCs per medical specialty are presented in table 1 . The five medical specialties with the highest expenditures (from high to low) were cardiology, surgery, internal medicine, orthopaedics and ophthalmology. Combined, these specialisms accounted for $66 \%$ of the total expenditures and $63 \%$ of the total number of DTCs. The five most expensive DTCs for these specialties are presented in the online supplemental tables 1-6.
Total annual patient expenditures divided into four categories (ie, primary care services excluding care related to $\mathrm{T} 2 \mathrm{DM}$, primary care services including care related to T2DM, secondary care and medication), for men and women, are presented in table 2. Total annual median expenditures per T2DM patient were €2133 (1161 to 3340) for men and €2535 (1374 to 5105] for women.

\section{Expenditures of T2DM versus control population}

The median per person expenditures were higher for patients with T2DM compared with the control group: the median expenditures were $€ 1031$ (281 to 2986) for men and $€ 1282$ (432 to 4507 ) for women. For patients with T2DM, the largest share of the healthcare expenditures was on medication: $€ 546$ (59 to 1076) for men and $€ 661$ (309 to 1285) for women. For the control group, secondary care accounted for the largest share of the total median per person expenditures. As presented in the supplemental material (see online supplemental table 7 ), the mean total per patient expenditures for both men and women were around two times as high as the median total expenditures, which suggests that a small part of the studied population is responsible for a considerable part of expenditures.

As presented in table 3, the largest difference in mean per patient expenditures for the T2DM and the control group was found for cardiology. The cardiology expenditures for T2DM patients were higher than the control group for both men ( $€ 548$ vs $€ 357$, difference $€ 191$ ) and women ( $€ 381$ vs $€ 221$, difference $€ 160$ ). Similar trends were seen for the mean per patient expenditures for cardiopulmonary surgery, gastroenterology, neurology, pulmonary medicine, general surgery and urology, which were all higher for patients with T2DM compared with patients without T2DM.

\section{DISCUSSION}

This study provides insights into the distribution of healthcare expenditures for primary care, secondary care and medication among Dutch patients with T2DM who receive diabetes treatment in the primary care setting. The expenditures for persons with T2DM were approximately twofold higher than those for persons without diabetes. Median total per T2DM patient expenditures were $€ 2133$ for men and $€ 2535$ for women, whereas median per person expenditures in the control group were $€ 1031$ for men and $€ 1282$ for women. Healthcare expenditures showed a skewed distribution, suggesting that a small part of the T2DM population is responsible for a considerable part of the costs.

The largest part of healthcare expenditures was spent on medication and on the medical specialty cardiology. Expenditures on cardiology can be explained by development of type 2 diabetes-related complications and subsequent intensive treatment. ${ }^{15}$ We observed that expenditures for the medical specialty orthopaedics were 
Table 1 Secondary care expenditures and number of DTCs for T2DM patients $(\mathrm{N}=43775)$



DTC, diagnosis treatment combination; T2DM, type 2 diabetes mellitus.

higher than for ophthalmology and neurology (data presented in online supplemental materials). For orthopaedics, 'arthrosis' was the most frequently reimbursed DTC. The relationship between T2DM, obesity and the development and progression of arthrosis could underly this finding. ${ }^{16}$ However, as persons with T2DM are prone to develop retinopathy and neuropathy, we did expect that expenditures on ophthalmology and neurology would be higher than those for orthopaedic treatments. Although speculative, as prevention and treatment guidelines of the integrated diabetes care programme enable most patients with retinopathy and neuropathy to be treated in primary care, this may translate into lower costs for secondary care. For the medical specialty internal medicine, 'diabetes mellitus with secondary complications' is the DTC with the highest cumulative expenditures. This seems remarkable because the patients with T2DM in our study population primarily receive their diabetes care in the primary care setting. However, increasing complexity of the patients' disease may lead to more secondary care referral for other morbidities besides diabetes.

Expenditures for cardiology had the largest discrepancy between patients with and without T2DM (mean difference for men $€ 191$ and for women $€ 160)$. This can be explained by the relatively higher cardiovascular morbidity and mortality in patients with T2DM. ${ }^{8-10}$ Patients with T2DM are two times as likely to develop cardiovascular disease compared with patients without T2DM, independent of age, smoking, BMI and systolic blood pressure. ${ }^{17}$ In addition, it is stated that cardiovascular disease develops approximately 15 years earlier in patients with T2DM as compared with persons without T2DM. ${ }^{15}$ Moreover, we found that the difference in per patient expenditures for cardiology women with and without T2DM is smaller than these are for men. Although hypothetical, this may indicate under recognition or under treatment of cardiovascular disease among women. 
Table 2 Median per patient expenditures for men and women with and without T2DM in Euro

\begin{tabular}{|c|c|c|c|c|c|c|}
\hline & \multicolumn{3}{|l|}{ Men } & \multicolumn{3}{|l|}{ Women } \\
\hline & $\begin{array}{l}\text { Patients with T2DM } \\
(n=18248)\end{array}$ & $\begin{array}{l}\text { Control group } \\
(n=36495)\end{array}$ & Difference & $\begin{array}{l}\text { Patients with T2DM } \\
(n=18992)\end{array}$ & $\begin{array}{l}\text { Control group } \\
(n=37985)\end{array}$ & Difference \\
\hline Secondary care & $\begin{array}{l}512 \\
(122-1494)\end{array}$ & $\begin{array}{l}307 \\
(0-1408)\end{array}$ & 205 & $\begin{array}{l}564 \\
(148-2018)\end{array}$ & $\begin{array}{l}367 \\
(40-1880)\end{array}$ & 197 \\
\hline Medication & $\begin{array}{l}546 \\
(59-1076)\end{array}$ & $\begin{array}{l}171 \\
(29-557)\end{array}$ & 375 & $\begin{array}{l}661 \\
(309-1285)\end{array}$ & $\begin{array}{l}236 \\
(239-635)\end{array}$ & 425 \\
\hline
\end{tabular}

Data are presented as median (IQR) costs in Euros.

Difference is based on costs, patients with T2DM minus the control group.

T2DM, type 2 diabetes mellitus.

When analysing healthcare costs for T2DM care andin particular-when comparing costs between patients with and without T2DM, it should be taken into account that the total healthcare expenditures for T2DM patients are not always necessarily directly attributable to diabetes. It should also be noted that the skewed distribution of expenditures found in this study suggests that expenditures per patient with T2DM vary and that a small part of the studied population is responsible for a considerable part of the costs. Findings from a recent Dutch study, including persons with T2DM diabetes (40\%), suggest that 'high-need, high-cost' patients tend to have a combination of somatic and psychiatric disorders as well as socioeconomic disparities. $^{18}$

In Germany, mean costs per person with T2DM were $€ 4957^{7}$ in 2010 . These costs were $€ 3661$ (in 2003) in Italy and $€ 2578$ (in 2010) in the UK. ${ }^{6}{ }^{19}$ This is somewhat lower as compared with the mean expenditures $(€ 4603( \pm 7871)$ for men and $€ 4757( \pm 7192)$ for women) found in this study. However, when compared with median costs found in this study (€2133 (1161 to 3340 ) for men and $€ 2535$ (1374 to 5105) for women), these costs are higher. Obviously, this non-parametric distribution of expenditures in the current study hampers proper comparisons of the healthcare expenditures for T2DM in the Netherlands with other countries. Comparisons are also hampered by the inclusion of persons treated (primarily) in secondary care in the costs of other countries. Nevertheless, knowledge of the distribution of healthcare costs and comparisons with other countries/healthcare systems could be of use for healthcare planning and policy making.

The present study has limitations. The data we showed are from 2011 and may, therefore, be to a certain extent outdated. As a result of stricter legislation, we were unable to combine more recent data from the clinical and APCD databases. Besides changes in total costs, it is conceivable that over the past years, more variations occurred in expenditures. Importantly, as glucose-lowering drugs such as glucagon-like peptide 1 receptor agonists and sodium-glucose cotransporter-2 inhibitors deserved a more prominent in treatment algorithms and there has been an increase in the use of technology (in particular, glucose sensors), this could have resulted in an increase in costs for medication over the past years. However, the data from 2011 did enable us to provide valuable insight into the distribution of healthcare expenditures for persons with T2DM and into differences in expenditures between persons with and without T2DM. The present study is also limited by lack of data concerning presence of complications of diabetes and glycaemic control.

Our analyses showed that health insurance data can be used to gain insight into healthcare expenditures for primary care, for secondary care (ie, per specialism, per DTC) and medication. This enables hypothesis making for future research. For instance, the health insurance data can potentially be used to calculate incidence and prevalence figures using the data from DTCs, especially if they are matched with existing pharmaceutical costs. Furthermore, a comparison of expenditures on patients with and without T2DM over a longer period of time can be made to obtain a meaningful insight into changes in healthcare costs over the years. Additionally, it would be interesting to identify patients with T2DM who make the bulk of the expenditures and study their characteristics. 
Table 3 Mean per patient expenditures per medical specialty for men and women with and without T2DM

\begin{tabular}{|c|c|c|c|c|c|c|}
\hline \multirow[b]{2}{*}{ Medical specialty } & \multicolumn{3}{|l|}{ Men } & \multicolumn{3}{|c|}{ Women } \\
\hline & T2DM & Control group & Difference & T2DM & Control group & Difference \\
\hline Allergology & 0.2 & 0.3 & -0.1 & 0.6 & 0.6 & 0.0 \\
\hline Anaesthesiology & 19.5 & 17.1 & 2.5 & 35.1 & 29.9 & 5.2 \\
\hline Audiology & 4.4 & 3.2 & 1.2 & 2.5 & 2.4 & 0.2 \\
\hline Cardiology & 547.7 & 357.1 & 190.6 & 381.3 & 221.4 & 159.9 \\
\hline Cardio-pulmonary surgery & 89.1 & 65.4 & 23.8 & 43.6 & 22.9 & 20.7 \\
\hline Clinical geriatrics & 7.4 & 25.7 & -18.3 & 10.8 & 33.4 & -22.6 \\
\hline Consultative psychiatry & 0.2 & 0.7 & -0.5 & 0.1 & 0.7 & -0.5 \\
\hline Dermatology & 44.5 & 42.2 & 2.3 & 42.0 & 44.9 & -2.9 \\
\hline ENT & 43.9 & 49.9 & -6.0 & 34.3 & 35.9 & -1.6 \\
\hline Gastro-enterology & 73.4 & 61.2 & 12.3 & 75.7 & 62.8 & 12.9 \\
\hline Gynaecology & 0.3 & 0.2 & 0.1 & 60.5 & 51.2 & 9.3 \\
\hline Internal medicine & 250.2 & 252.8 & -2.6 & 274.3 & 252.3 & 22.0 \\
\hline Genetics & 0.8 & 0.8 & 0.0 & 1.6 & 1.2 & 0.4 \\
\hline Neurology & 112.7 & 98.8 & 13.9 & 102.7 & 90.6 & 12.1 \\
\hline Neurosurgery & 27.0 & 24.5 & 2.5 & 30.1 & 21.9 & 8.2 \\
\hline Ophthalmology & 129.1 & 96.5 & 32.6 & 149.5 & 122.8 & 26.7 \\
\hline Orthopaedics & 139.2 & 135.9 & 3.3 & 262.6 & 243.3 & 19.3 \\
\hline Paediatrics & 0.0 & 0.0 & 0.0 & 0.0 & 0,0 & 0.0 \\
\hline Plastic surgery & 17.8 & 19.5 & -1.7 & 24.2 & 24.9 & -0.6 \\
\hline Pulmonology & 140.8 & 128.6 & 12.2 & 106.4 & 91.0 & 15.5 \\
\hline Radiology & 19.6 & 13.3 & 6.3 & 13.5 & 9.7 & 3.8 \\
\hline Radiotherapy & 48.6 & 55.5 & -6.9 & 42.8 & 47.7 & -5.0 \\
\hline Rehabilitation & 37.7 & 48.4 & -10.7 & 35.6 & 37.4 & -1.8 \\
\hline Rheumatology & 16.2 & 19.3 & -3.2 & 24.1 & 27.8 & -3.7 \\
\hline General surgery & 298.4 & 248.5 & 49.9 & 271.2 & 260.5 & 10.7 \\
\hline Urology & 168.8 & 156.1 & 12.7 & 54.9 & 34.8 & 20.10 \\
\hline
\end{tabular}

Expenditures are presented in Euros as an average.

CG, control group; ENT, ear, nose and throat physician; T2DM, type 2 diabetes mellitus-group; $\Delta$, Costs T2DM - CG.

\section{CONCLUSIONS}

This study is the first to provide a comprehensive overview of primary care, secondary care and medication expenditures for patients with T2DM who receive diabetes care in the primary care setting. Per person expenditures for persons with T2DM were approximately twofold higher than those for persons without diabetes. The largest part of these expenditures was spent on medication and on the medical specialty cardiology. The skewed distribution of the data suggests that a small part of the studied population is responsible for a large share of expenditures. More research with health insurance claims data, also in larger populations, is needed to further exploit the potential of APCDs. Using these data, healthcare planning and policy making can find support in their decision making.

Author affiliations

${ }^{1}$ Internal Medicine, University of Groningen, University Medical Center Groningen, Groningen, The Netherlands
${ }^{2}$ Health Services Research, Maastricht University, Maastricht, Limburg, The Netherlands

${ }^{3}$ Human Capital Care, Hengelo, The Netherlands

${ }^{4}$ Department of Health Services Research, Maastricht University, Maastricht, The Netherlands

${ }^{5}$ Endocrinology, University of Groningen Faculty of Medical Sciences, Groningen, The Netherlands

${ }^{6}$ Department of Endocrinology, University of Groningen, University Medical Center Groningen, Groningen, The Netherlands

Twitter Arianne Elissen @ArianneElissen

Contributors MRJM: design, statistical analysis, interpretation of data, writing manuscript. RJG: critically reviewing manuscript. SHH: design, interpretation of data, critically reviewing manuscript. AE: critically reviewing manuscript. PRvD: design, statistical analysis, interpretation of data, writing manuscript. HJGB: design, supervision, interpretation of data, writing manuscript, critically reviewing manuscript. HJGB is the guarantor of the work.

Funding This research was funded from various sources, including the Isala Academy in Zwolle. The Netherlands, and a grant from the Diabetes Research Center in Zwolle, the Netherlands.

Competing interests None declared. 
Patient consent for publication Not applicable.

Ethics approval Because retrospective studies with anonymised data do not require approval within the framework of the Dutch CCMO, an approval from the Medical Ethics Review Committee based on the formal rules of the CCMO was not required in 2014 (the year of linking the data).

Provenance and peer review Not commissioned; externally peer reviewed.

Data availability statement Data are available upon reasonable request.

Supplemental material This content has been supplied by the author(s). It has not been vetted by BMJ Publishing Group Limited (BMJ) and may not have been peer-reviewed. Any opinions or recommendations discussed are solely those of the author(s) and are not endorsed by BMJ. BMJ disclaims all liability and responsibility arising from any reliance placed on the content. Where the content includes any translated material, BMJ does not warrant the accuracy and reliability of the translations (including but not limited to local regulations, clinical guidelines, terminology, drug names and drug dosages), and is not responsible for any error and/or omissions arising from translation and adaptation or otherwise.

Open access This is an open access article distributed in accordance with the Creative Commons Attribution Non Commercial (CC BY-NC 4.0) license, which permits others to distribute, remix, adapt, build upon this work non-commercially, and license their derivative works on different terms, provided the original work is properly cited, appropriate credit is given, any changes made indicated, and the use is non-commercial. See: http://creativecommons.org/licenses/by-nc/4.0/.

\section{ORCID iDs}

Rose Julie Geurten http://orcid.org/0000-0002-4638-8114

Arianne Elissen http://orcid.org/0000-0001-9795-8095

Peter Ruben van Dijk http://orcid.org/0000-0002-9702-6551

\section{REFERENCES}

1 Cho NH, Shaw JE, Karuranga S, et al. IDF diabetes atlas: global estimates of diabetes prevalence for 2017 and projections for 2045. Diabetes Res Clin Pract 2018;138:271-81.

2 Marín-Peñalver JJ, Martín-Timón I, Sevillano-Collantes C, et al. Update on the treatment of type 2 diabetes mellitus. World $J$ Diabetes 2016;7:354-95.

3 Diabetes mellitus type 2 in de tweede lijn [Internet]. Federatie Medisch Specialisten, 2018. Available: http://www.zorgstandaarddia betes.nl/wp-content/uploads/2018/10/Diabetes_mellitus_type_2_in_ de_tweede_lijn.pdf

4 van Hateren KJJ, Drion I, Kleefstra N, et al. A prospective observational study of quality of diabetes care in a shared care setting: trends and age differences (ZODIAC-19). BMJ Open 2012;2. doi:10.1136/bmjopen-2012-001387. [Epub ahead of print: 2908 2012].

5 Barents E, Bilo H, Bouma M, et al. Diabetes mellitus type 2 | NHGRichtlijnen, 2018. Available: https://richtlijnen.nhg.org/standaarden/ diabetes-mellitus-type-2 [Accessed 15 Feb 2021].

6 Bruno G, Picariello R, Petrelli A, et al. Direct costs in diabetic and non diabetic people: the population-based Turin study, Italy. Nutr Metab Cardiovasc Dis 2012;22:684-90.

7 Jacobs E, Hoyer A, Brinks R, et al. Healthcare costs of type 2 diabetes in Germany. Diabetic Medicine 2017;34:855-61.

8 Lee WL, Cheung AM, Cape D, et al. Impact of diabetes on coronary artery disease in women and men: a meta-analysis of prospective studies. Diabetes Care 2000;23:962-8.

9 Peters SAE, Huxley RR, Woodward M. Diabetes as risk factor for incident coronary heart disease in women compared with men: a systematic review and meta-analysis of 64 cohorts including 858,507 individuals and 28,203 coronary events. Diabetologia 2014;57:1542-51.

10 Roche MM, Wang PP. Sex differences in all-cause and cardiovascular mortality, hospitalization for individuals with and without diabetes, and patients with diabetes diagnosed early and late. Diabetes Care 2013;36:2582-90.

11 Kautzky-Willer A, Harreiter J, Pacini G. Sex and gender differences in risk, pathophysiology and complications of type 2 diabetes mellitus. Endocr Rev 2016;37:278-316.

12 Ubink-Veltmaat LJ, Bilo HJG, Groenier KH, et al. Prevalence, incidence and mortality of type 2 diabetes mellitus revisited: a prospective population-based study in the Netherlands (ZODIAC-1). Eur J Epidemiol 2003;18:793-800.

13 Ubink-Veltmaat LJ, Bilo HJG, Groenier KH, et al. Shared care with task delegation to nurses for type 2 diabetes: prospective observational study. Neth J Med 2005;63:103-10.

14 Vektis. Missie \& visie | Vektis.nl [Internet]. Vektis, 2020. Available: https://www.vektis.nl/over-vektis/missie-en-visie [Accessed 15 Feb 2021].

15 Beckman JA, Paneni F, Cosentino F, et al. Diabetes and vascular disease: pathophysiology, clinical consequences, and medical therapy: Part II. Eur Heart J 2013;34:2444-52.

16 Duclos M, Osteoarthritis DM. Osteoarthritis, obesity and type 2 diabetes: the weight of waist circumference. Ann Phys Rehabil Med 2016;59:157-60.

17 Emerging Risk Factors Collaboration, Sarwar N, Gao P, et al. Diabetes mellitus, fasting blood glucose concentration, and risk of vascular disease: a collaborative meta-analysis of 102 prospective studies. Lancet 2010;375:2215-22.

18 Smeets RGM, Elissen AMJ, Kroese MEAL, et al. Identifying subgroups of high-need, high-cost, chronically ill patients in primary care: a latent class analysis. PLoS One 2020;15:e0228103.

19 Einarson TR, Acs A, Ludwig C, et al. Economic burden of cardiovascular disease in type 2 diabetes: a systematic review. Value Health 2018;21:881-90. 